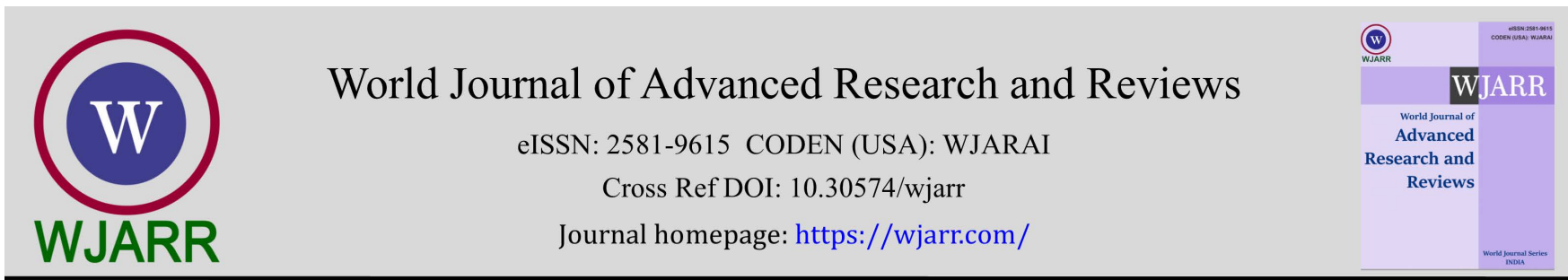

(RESEARCH ARTICLE)

Check for updates

\title{
To explore how stress and depression associates with wellbeing of university students in Eastern Nigeria by gender
}

\author{
Ezenna Michael Agwu * \\ Department of Public Health, Mother Teresa Public Health Research Center, Aba, Abia State, Nigeria.
}

World Journal of Advanced Research and Reviews, 2021, 10(01), 312-322

Publication history: Received on 27 February 2021; revised on 30 March 2021; accepted on 31 March 2021

Article DOI: https://doi.org/10.30574/wjarr.2021.10.1.0137

\begin{abstract}
Background: Few studies in the past examined student's health status and lifestyle behaviours, however, none have examined how student's wellbeing is being influenced by stress and depression among university students in eastern Nigeria. This is the first study in Nigeria to gauge the relationship between students mental health status with wellbeing. The study went further to examined how the relationship of stress and depression transmits through gender among the students.
\end{abstract}

Aims: The aim of this study is to explore the relationship of stress and depression with students' wellbeing and gender.

Method: This is a cross sectional descriptive study. Full time university students were recruited from the department of public health in the University of Calabar, Cross River state Nigeria. Data collection was based on an anonymous questionnaire and the sample size was $(n=291)$. Descriptive tests and chi-square tests were conducted.

Results: The study indicated that female students reported higher stress and depression than their male counterparts. Secondly the study shows that female students had a better wellbeing and health status than male students.

Conclusion: This study is the first to gauge the association of stress and depression with wellbeing and gender of university students in Nigeria. The result indicated that though female students reported higher stress and depression than male students however, on the contrary they reported better wellbeing index than their male counterparts that even reported lower stress and depression.

Keywords: Depression; Stress; Psychosocial; Gender; Wellbeing; Health status; Psychological health; Stressors

\section{Introduction}

According to the World Health Organization [7], "Health is a state of complete physical, mental and social well-being and not merely the absence of disease or infirmity." Conversely, [8] argued that the WHO definition of health as "complete wellbeing" is no longer fit for purpose given the rise of non-communicable diseases (NCDs) such as stress or depression. Consequently, [8] proposed an alternative definition, which includes changing the emphasis towards "the ability to adapt and self-manage in the face of social, physical, and emotional changes and to function with fulfilment and a feeling of wellbeing with a chronic disease or disability." Although, WHO [1] in order to include concepts like stress and depression have elaborated on their earlier definition of health, by adding, "Wellbeing is the optimal stage of health of individuals and groups." This concept of wellbeing is significant, because it encompasses the realization of the fullest potential of an individuals' health, physically, mentally and socially.

\footnotetext{
* Corresponding author: Dr. Agwu Michael Ezenna; Email: ezenna2015@yahoo.com

Department of Public Health Mother Teresa Public Health Research Center, Aba, Abia State, Nigeria.
} 
Measuring the wellbeing and the factors that can influence it such as stress or depression among university students in Nigeria is important to ascertaining health intervention effectiveness, monitoring progress, and as a critical step in measuring the health of the general population. Moreover, in Nigeria, the population of young adults in the university are significant, about (8.1\%) of the total age group (15-64) that constitute about (54.9\%) of the total population of Nigeria [9]. Consequently the wellbeing of university students is not only important for them, but also relevant to policies concerning health. Furthermore, students are future leaders and potential policy makers, their health and wellbeing need to be guided at this most important phase of their development, and equipped with the right knowledge to be able to distinguish between healthy and unhealthy lifestyles [10].

With regard to university students in Nigeria, there is evidence that the transition to university is difficult [11, 12]. There is evidence that conditions in colleges and campuses are poor, with problems of accommodation, overcrowded lecture halls, unavailable learning materials, irregular electricity, poor transport facilities and poor health facilities [13, 14].These unfavorable conditions in the learning environment, can initiate stress and then depression, that will eventually compromise the students wellbeing and health status. The aim of this study is to gauge how student's wellbeing by gender is affected by stress and depression. This study is the first to examine this relationship among university students in Nigeria and will definitely fill a gap in knowledge and as well make a contribution to literature.

\subsection{Background of the study}

Nigeria is the most populous country in sub-Sahara Africa with an estimated area of 923,773 km2 [14, 15]. comprising of 36 states and a population of 152 million people. Based on natural landscape, Nigeria is divided into three regions namely: Northern region, Western region and Eastern region, by the intersection of the River Niger and the River Benue (Figure 1) before terminating into the Gulf of Guinea [16]. The geographical location of the Federal Republic of Nigeria is on the Gulf of Guinea in the West Africa.

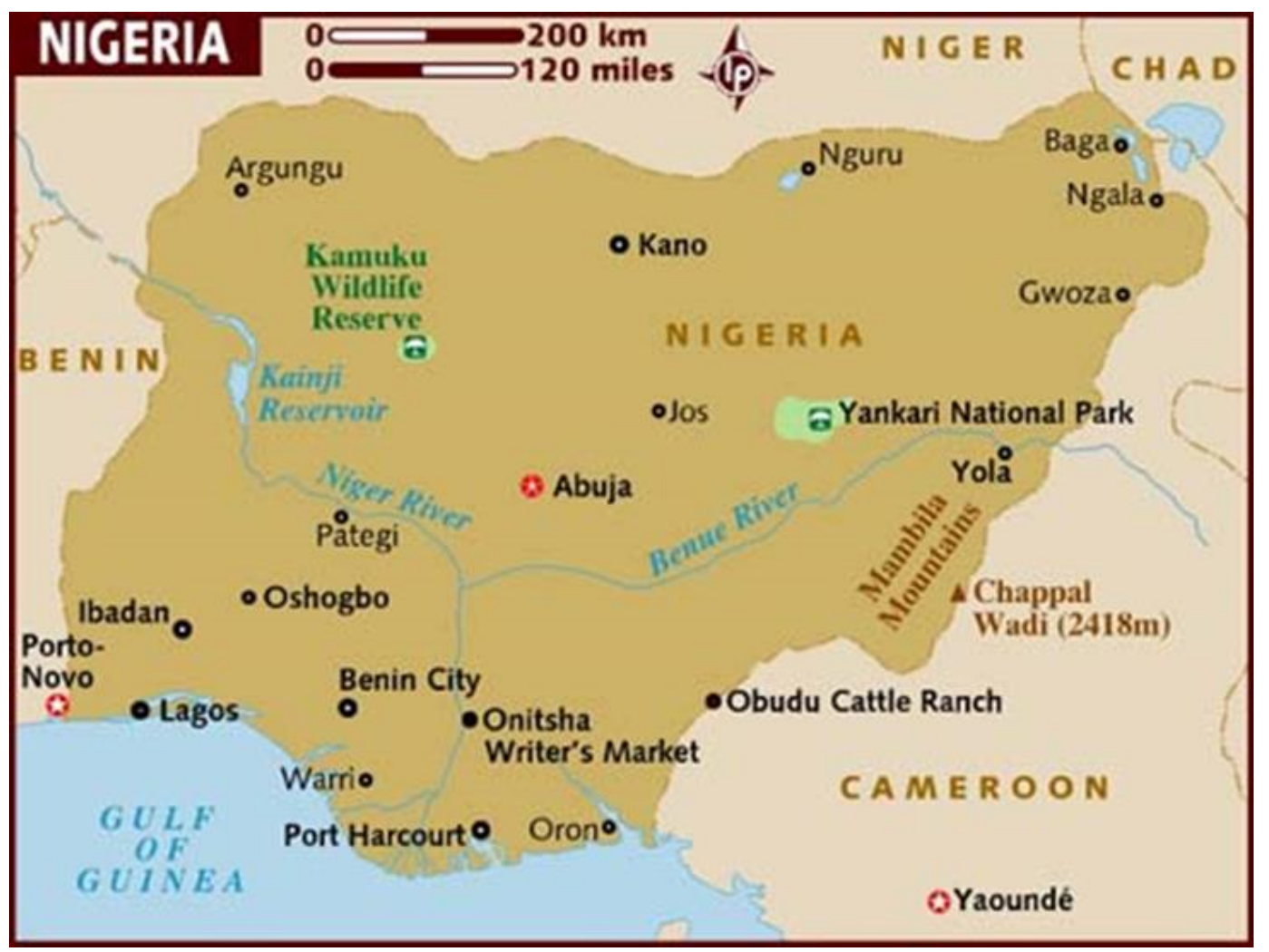

Figure 1 Map of Nigeria showing the three regions by the intersection of the Niger River.

It is between Benin in the west and Cameroon in the east, in the north east is Chad and Niger in the north-west. The diversity of climates observed in Nigeria are aridity in the North, tropical in the center, and equatorial in the South, with a maximum temperature above 32 degrees Celsius in the North [17]. The annual rainfall is more in the South 2000 millimeters than in the North 500-700 millimeters [15]. Therefore, the Northern region is exposed to a prolonged heat, prolonged drought, and dry seasons, this hash environmental conditions is expected to affect growing of crops, vegetation, and grazing of animals, sources of domestic water and sanitation and farming among others. 
Consequently, it is assumed that the environmental conditions will affect both the physical health and psychological health of Nigerians living in the Northern region, differently from those living in the other two regions. However, no comparative cultural study exists in Nigeria that examined the wellbeing of university students and its relations to stress and depression by gender among the three regions in Nigeria. This study intends to provide the first baseline information with regards to the association of stress and depression with wellbeing among university students in eastern Nigeria.

\subsection{Mental health status}

There is no universally accepted definition of mental health. However, according to [18], "mental health is operationalized as a syndrome of symptoms of an individual's subjective well-being" (p. 207). On the other hand, the WHO [7] defined mental health as: "a state of well-being in which the individual realizes his or her own abilities, can cope with the normal stresses of life, can work productively and fruitfully, and is able to make a contribution to his or her community". However,[19] argued that the determinants of both positive mental well-being and mental health problems include a mix of biological, psychological, social and environmental factors that are difficult to determine. Most of these factors are already discussed in the theoretical model that underpins the current study presented in the last section.

There is evidence that demographic factors (e.g. gender and ethnicity) together with student's lifestyles (e.g. physical activity, diet, alcohol consumption and smoking), correlated with students mental health status [11; 20; 21]. Similarly, studies has shown that the rates of psychological ill-health among university students are increasing and identifying modifiable risk factors for students psychological health becomes increasingly important, given the persistence of students psychological health into adulthood [22]. Consequently, the mental health condition of university students is a public health issue in both developed and developing countries and many young adults may experience their first psychiatric episode during their time at the university [23]. In a large study conducted by the American College Health Association [24] with a population of $(n=47000)$ students from 74 American colleges. The result showed significant increase of students' mental health; from $8 \%$ to $23 \%$ with $10 \%$ contemplated suicide $14 \%$ reported depression while $63 \%$ reported feeling of hopeless.

Although, several studies examined the factors associated with students mental health, however, only few studies examined how these factors are distributed by gender and ethnicity, despite the evidence that these two demographic factors contributes to health inequality [25; 26]. The following section examined previous studies with regard to stress and depression the two major mental health indicator among university students.

\subsection{Depression and stress}

According to the World Federation for Mental Health "depression is a common mental disorder, characterized by sadness, loss of interest or pleasure, feelings of guilt or low self-worth, disturbed sleep or appetite, feelings of tiredness and poor concentration" (2009), p. 3. Consequently, an individual who has good mental health will be able to realize his or her own abilities, can cope with the stress of everyday life, be able to work productively and contribute to his or her community [7]. On the other hand, [28] defined stress as: "All physical, psychological or social phenomena that tax or exceed an organism in such a way that physical, psychological or social change results"

However, the factors associated with depression and stress are well documented among the elderly population [29], why the factors associated with depression and stress among young adults in the university has not been established, especially with regard to gender. Students commonest challenge to depression is stress [12; 30] and several factors have been reported to increase stress among university students. These factors include: Academic workload, [31] chronic illness [32; 22; 33], financial problems [32; 31; 34].

Although, many factors contributing to students stress have been wildly reported, however, most of the findings are contradictory or inconclusive. [12], in a cross sectional study examined the sources of stress among a convenience sampled medical students $(n=77)$ in a university in western Nigeria. The result showed that $48 \%$ of students reported stress related to academic workload, and another 38\% reported stress due to financial problems. Other studies by [30] reported similar findings.

The important of income status as a major contribution in students stress and depression was also highlighted in a study among $(n=492)$ students in a university in Iran by [22]. The result showed that $(48 \%)$ of the total sample reported major depression, of which (44\%) of the students indicated that their depression was related to financial problems. However, stress and depression regarding to students' academic workload was not reported. Also, a study by Marshall 
et al. [35] among a convenience sampled pharmacy students in US $(n=109)$, found that stress as a result of academic related problems correlated negatively with students depression and mental health status.

Marshall et al. [35] argued that their result may be due to the young age and good physical health of their participants, which may serve as a cushion for stress. Conversely, [35] noted that their study has some limitations. They attributed their findings to small sample size, and consequently called for more studies with a larger sample of university students. Other studies $[36,37]$ reported that though university students have significant degrees of recorded stress, which was associated more to student's year of study and not due to their academic workload or a quest for high performance.

More so, there is evidence that first-year undergraduates have elevated risk of depression and stress than other students $[5 ; 37 ; 36]$. This finding was explained on the basis that transition to adulthood represents a stressful period to young students and this may present a high risk for the onset of depression [34]. On the contrary, higher frequency of depression among students in higher academic years was reported by other studies [33; 38]. However, there is a need to understand the group of factors that contribute to students' academic related stress and depression.

More so, most of the studies examined called for more investigations so as to understand the direction of this important association [34; 33]. However, despite research findings that indicated positive correlation between depression and stress with wellbeing indicators such as obesity, hypertension and sleep disturbances, even suicidal ideation and suicide, yet very few studies seemed to be focused on the effects of depression and stress on the wellbeing of university students especially in Nigeria.

There is evidence that certain wellbeing indicators like obesity, hypertension and body image perception are associated with students stress and depression [32; 33]. For example, an earlier study by [39] which investigated the correlation between chronic stress, depression and general health problems among $(n=150)$ students from a university in the United States. The result revealed a positive correlation between students stress, depression and hypertension. Similarly [40] examined symptoms of depression among a sample $(n=64)$ of Estonian medical students with sleep problems.

The result showed a positive correlation between sleeps disturbances (e.g. insomnia) with depression, which was attributed to the fact that mental disorders may have a negative effect on the course of physical illness. Furthermore, gender differences in student's perception of depression and stress have been reported but the findings were controversial. While some studies found that female students reported depression more than female students [34]. In contrast, [31] found no significant differences between male and female students.

On the other hand, [41] examined the prevalence of depressive symptoms among a convenience sample of $(\mathrm{n}=262)$ students in a university in Nigeria. The result showed that (23.3\%) of the total sample reported depression. In addition, the study also showed that female students reported higher rate of depression than male students. However, [22] suggested that the higher ratio of female students (in sample size) to male students in most studies might help to explain the observed higher frequency of female students reporting depression than male students. They recommended that in conducting research that involves analysis by gender, that the researcher must ensure similarity of the sample. [42] examined the prevalence of stress and depression among medical students in a university in Norway $(n=342)$. The result showed that with regard to depression, more female students compared to male students, reported depression but with regard to stress, the study showed no gender differences. Hover, [43] postulated that gender differences in stress and depression among university students might be due to women's stronger determination to succeed academically, which might give rise to a greater level of stress. Secondly, that women report more illness than men do, because of men's reluctance to admit illness rather than to the actual incidence of illness among women. These conflicting results suggested that further study of sex differences in student's health status might benefit from the examination of students health and wellbeing.

\section{Research Method}

\subsection{Consent and Confidentiality}

However, the present study involved only healthy and non-vulnerable adults from the age of 18 years, and no stage of the data collection involved any invasive procedure, emotional or psychological impact, However, the researcher sought permission to conduct the research from the Dean of the Faculty. A letter for approval was presented by hand directly to the Dean of the Faculty of Public health. The letter contained the required information concerning the research: title, objectives and the data collection techniques. The letter also explained that the participants consent would be sought before administering the questionnaire, and that their confidentiality will be assured by employing a self-anonymous 
questionnaire, which does not ask participants name, address or any other form of identification. The letter also explained that the participants have a right to withdraw from the study at any time without any legal implication therefore participation is voluntary. Prior to data collection, similar information was given to the participants.

\subsection{Sampling of Participants}

The samples for the current study were university students, drawn from the department of public health at the University of Calabar, Cross River State Nigeria The health survey was administered to 400 students of which 335 were returned and 291 respondents completed their questionnaire with the required data and were consequently entered for the analysis. To ensure that these samples have equal representation by the academic year of study, the intended sample $(\mathrm{n}=400 \pm 40)$ was shared among four academic years, allowing $(\mathrm{n}=100 \pm 10)$ students to be recruited from each academic year (e.g. 1, 2, 3, \& 4). However, since students were recruited from lecture rooms, the recruitment exercise for each year goes on, until the estimated number of participants was met.

\subsection{Data collection procedures}

Data were collected from students in the department of public health in the University of Calabar. The data collection took place between August and September 2019. Data collection was carried out by the use of anonymous questionnaire. The questionnaire was given to the participants during lecture with the entire student's on-sit. Giving students on hand in this form was a good strategy as it recorded a very high participation and completion rate. Data collection process lasted for about 40 minutes. Consequently, students' response to the questions in the present study was transferred to the SPSS statistical package, 20.0 versions, for analysis.

\subsection{Statistical data analysis for the present study}

\subsubsection{Descriptive statistics}

Preliminary data analysis of this study was conducted with descriptive tests. By conducting the descriptive tests, it was possible to check the entire data set entered into the SPSS for error. Descriptive tests enabled any error to be identified and corrected in the data set. In addition, descriptive statistics made it possible for the description of the characteristics of the sample in frequency and percentages. The Chi square test was employed to explore the relationship between categorical variables in the analysis. Chi square analysis provides information on the simple 'main effect' for the current study on sex and ethnicity, which enables the level of associations to be determined.

\section{Results}

A total of $(n=291)$ of the sample completed the questionnaire correctly and was computed into the SPSS version 20.0 for statistical analysis (Table 1).

Table 1 Frequency and percentages of variables used in the study.

\begin{tabular}{|l|l|l|}
\hline Variables & Frequency & Percentages \\
\hline Gender & & \\
Male & 100 & 34.4 \\
Female & 191 & 65.6 \\
\hline Monthly income & & \\
Always sufficient & 20 & \\
Mostly sufficient & 40 & 8.9 \\
Sometimes insufficient & 201 & 13.7 \\
Mostly insufficient & 15 & 69.1 \\
& & 9.3 \\
\hline Depressive index & & \\
Depressed & 102 & 35.1 \\
Not depressed & 188 & 64.9 \\
\hline
\end{tabular}




\begin{tabular}{|l|l|l|}
\hline Perceived stress & & \\
Stressed & 257 & 88.3 \\
Not stressed & 34 & 11.7 \\
\hline Wellbeing Index & & \\
High wellbeing & 233 & 80.1 \\
Low wellbeing & 58 & 19.1 \\
\hline
\end{tabular}

The descriptive analysis of the socio-demographic factors indicated there are more female students' (65.6\%) than their male counterparts (34.4\%). On the other hand students' age group analysis indicated that higher percentage of students belonged to the middle aged groups (57.4\%), while students in the oldest age category are the least in number ((3.4\%). With regard to income, more students reported their income to be 'sometimes insufficient' (69\%) compared to those students' that belonged to the income category 'mostly sufficient (9\%). The study indicated that why only (35\%) of students reported depression as much as (88\%) of the students reported high stress. On the other hands, the study indicated that as much as (80\%) of students reported their wellbeing to be high despite high stress (88\%).

\subsection{Wellbeing and mental health indicators}

With regard to the possible associations between wellbeing and mental health indicator (Table 2), the result indicated that among the students who reported depression, only (30.5\%) reported high wellbeing while those students who reported 'not depressed' more than (69\%) reported high wellbeing and the differences was significant ( $\mathrm{p}-\mathrm{v}=.002)$. Consequently, the study indicated that depression is associated with low wellbeing, which may equally affect the students general health status. With regard to stress and wellbeing the result indicated that at higher stress (86.3\%) of students reported higher wellbeing, whereas (96.6\%) of students reported low wellbeing. On the other hands, at a lower stress $(13.7 \%)$ of students reported higher wellbeing compared to only (3.7 \%) that reported higher wellbeing at a lower stress. Consequently, the study assumed of a possible relationship between stress and depression and the association was significant $(\mathrm{p}-\mathrm{v}=.051)$

Table 2 Frequency (\%) of wellbeing and gender with mental health indicators.

\begin{tabular}{|c|c|c|c|c|c|c|c|c|}
\hline Variables & $\begin{array}{l}\text { High } \\
\text { wellbeing }\end{array}$ & $\begin{array}{l}\text { Low } \\
\text { wellbeing }\end{array}$ & P-value & $\begin{array}{l}\text { Phi } \\
\text { value }\end{array}$ & Male & Female & $\begin{array}{l}P \text { - } \\
\text { value }\end{array}$ & $\begin{array}{l}\text { Phi } \\
\text { value }\end{array}$ \\
\hline $\begin{array}{l}\text { Depression } \\
\text { Depressed } \\
\text { Not depressed }\end{array}$ & $\begin{array}{l}71 / 30.5 \\
162 / 69.5\end{array}$ & $\begin{array}{l}31 / 53.4 \\
27 / 46.6\end{array}$ & .002 & -192 & $\begin{array}{l}26 / 25.5 \\
74 / 39.2\end{array}$ & $\begin{array}{l}76 / 74.5 \\
115 / 60.8\end{array}$ & .027 & -137 \\
\hline $\begin{array}{l}\text { Perceived -stress } \\
\text { Stressed } \\
\text { Not Stressed }\end{array}$ & $\begin{array}{l}201 / 86.3 \\
32 / 13.7\end{array}$ & $\begin{array}{l}56 / 96.6 \\
2 / 3.4\end{array}$ & .051 & -128 & $\begin{array}{l}84 / 32.7 \\
16 / 47.1\end{array}$ & $\begin{array}{l}173 / 67.3 \\
18 / 52.9\end{array}$ & .143 & -.097 \\
\hline $\begin{array}{l}\text { Gender } \\
\text { Male } \\
\text { Female }\end{array}$ & $\begin{array}{l}87 / 37.3 \\
146 / 62.7\end{array}$ & $\begin{array}{l}13 / 22.4 \\
45 / 77.6\end{array}$ & .047 & 126 & ${ }^{* *} \mathrm{NN}$ & ${ }^{* *} \mathrm{NN}$ & ${ }^{* *} \mathrm{NN}$ & ${ }^{* *} \mathrm{NN}$ \\
\hline
\end{tabular}

\subsection{Gender and mental health indicators}

With regard to gender and depression the study indicated that more female students (74.5\%) are depressed compared to their male counterparts (25.5\%), and the differences are shown to be statistically significant (.027) though the effect size was low (-.137). On the other hands, among students who reported 'not depressed' (69.5\%) reported high wellbeing whereas (46.5\%) reported low wellbeing. Consequently, depression seems to have negative effect on wellbeing (Table 2). 


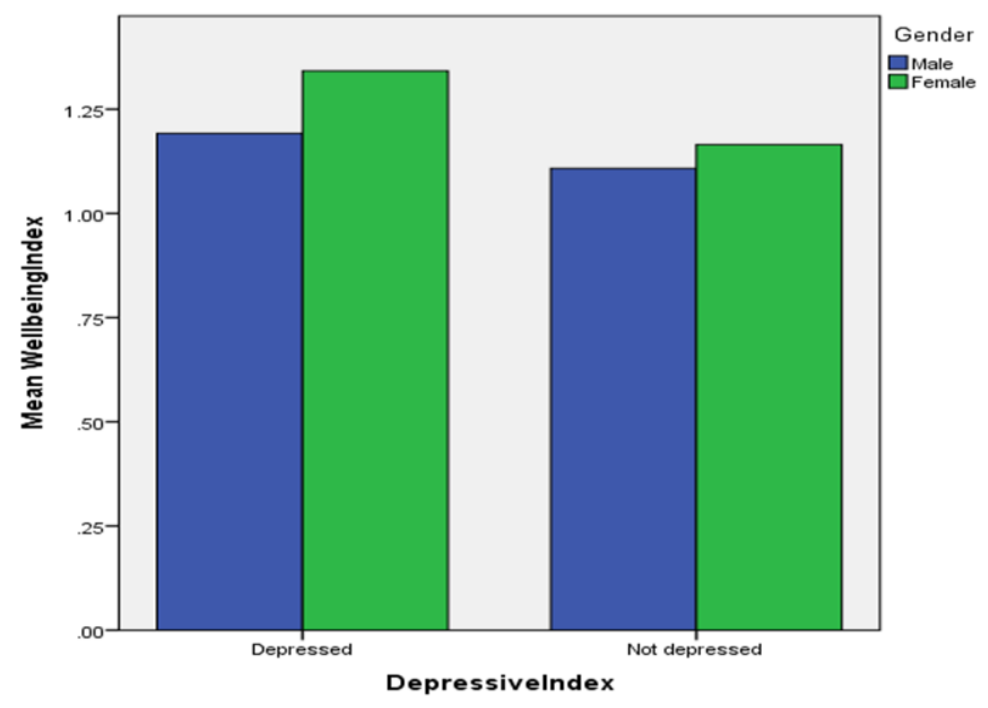

Figure 1 Showing the association of gender with depression and wellbeing

However, when the analysis was compared by gender, the result indicated that female students reported more depression than their male counterparts. Interestingly, female students reported better wellbeing than male students despite having more depressive symptoms than male students (Figure1).

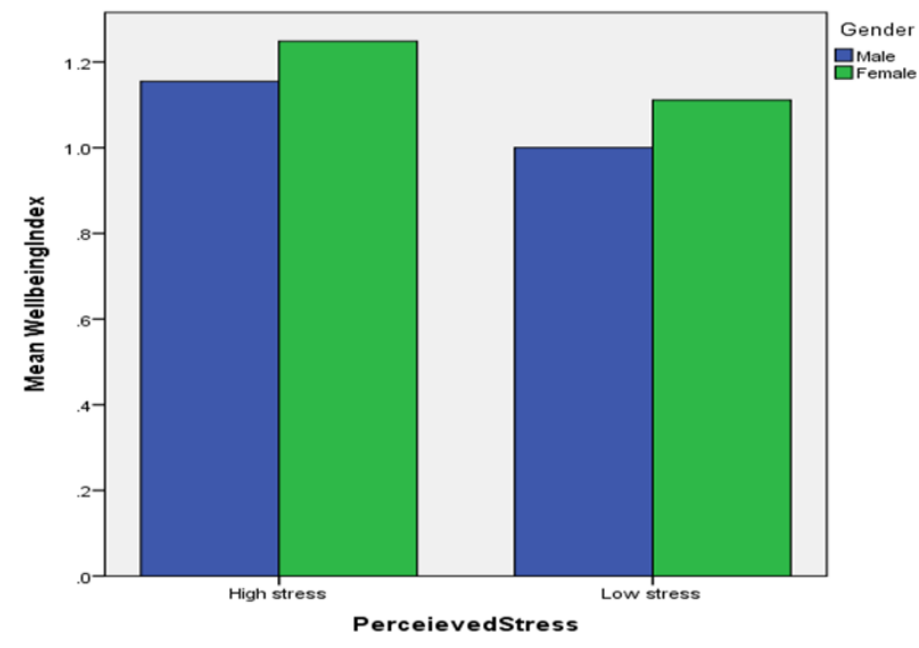

Figure 2 Showing the association of gender with stress and wellbeing

With regard to stress the study indicated that more female students reported stress than their female counterparts (Table 2 Figure 2). However, when students under stress were gauged with wellbeing, the result indicated that female students despite high stress reported better wellbeing than male students. The implication of the result is that possibly stress has no impact on wellbeing among female students.

\section{Discussion}

The aim of this study is to define the association between mental health indicators particularly depression and stress with students wellbeing and how these associations is defined further by gender. Descriptive statistics was obtained through codebook, while the association of items was examined by chi-square statistics. The demographic statistics revealed that there are more female students than males. Other previous studies with university students in Nigeria supported the findings that more females attend university in Nigeria than males $[23 ; 4 ; 44)$. The possible explanation for this gender disparity of university students may be associated with the support for women education by feminist and Non-governmental originations that are struggling for women liberation and the support of the Federal government of Nigeria for women education which stated in the late 1990s in Nigeria. More so, in recent times, the value of women in Africa and in Nigeria has improved remarkably, due to the activities of human rights and equality rights activists in 
Nigeria. Consequently, more women are now being supported and encouraged to go back to school, to avoid early pregnancy, early marriage and ill health [15].

More so the economic hardship in Nigeria have forced so many young boys to look for avenues for making quick money such as tricycle riders commonly called (keke na pepe) in Nigeria.

On the other hands, examination of students monthly income in Nigeria indicated that while only (8.9\%) of the students reported their monthly income to be always sufficient, over (69\%) of the students reported their income status to be ('sometimes insufficient' Table1).This is understandable, university education in Nigeria is very expensive in addition to the poor performance of the Nigerian economy and consequently students are on the receiving end of the hash economic condition hence the monthly allowance of university students is becoming 'sometimes in sufficient'.

However, since the Nigeria economy depend mainly on oil and agriculture [45; 15], consequently, the current fall of oil price worldwide, is affecting the economy of all the oil producing nations, such as Russia, Iran, Libya, Kuwait [46]. In addition, the high cost of living in Nigeria has made most of the students to be reporting income 'always insufficient.' Moreover, the agricultural sector, another source of income in Nigeria is affected by the high rate of violence and killing of farmers who went to their farm in Nigeria by the militants (Boko Haram) making things very difficult especially for students who depend on family members and friends for financial help. Despite the fact that low income and income insufficiency are such a fundamental aspect of low socioeconomic status, however, the evidence for their role in generating health inequalities is far from complete $[47 ; 48 ; 32 ; 34]$. On the other hand, there is evidence that incomerelated indicators of socioeconomic status, such as social support, monthly and household income are strong predictors of ill health $[49 ; 1 ; 22]$. There is a sharp contrast between income status among students in developing countries like Nigeria and those of developed countries. For instance, a study conducted among students from Spain and Germany [53] found (72\%) and (64\%) of students respectively, reported their income to be always sufficient. In developed countries and in most western European countries, students especially university students receive financial aids, through government funding and bank loans which are not available for Nigerian students. Consequently, many students from these countries have sufficient funds for their education, in addition to part time jobs. This makes a poor comparison with the current study where most of the students are mostly self-sponsored. There is no doubt that students mental health in Nigeria may be affected by the unfavorable economic conditions in Nigeria as noted by [23; 4].

With regard to the impact of depression and stress on students' wellbeing, the study noted that students who reported high wellbeing also reported low depression and stress, on the contrary, those who reported high depression and stress reported low wellbeing. Consequently the current studies argued that depression and stress have a negative impact on students' general health status. The reasons for the high prevalence of depression and stress in the current study might be related to the observations, that university education in Nigeria is associated with difficulties [12; 23]. Some of these difficulties are related to: poor income status, income insufficiency, poor health and poor accommodation, violence within university campuses by Islamist militants, in addition to poor infrastructural facilities [12; 23; 51]. Consequently, the effect weighs down on students general health and wellbeing. Similar findings was also reported by previous studies on the negative health impact of depression and stress on students health status and wellbeing e.g. [32; 22; 33].

With regard to the impacts of stress and depression on students wellbeing by gender, the result indicated that female students reported more stress and depression than male students,(Table2, Figure 2). Other studies have also found that more female students reported depression than male students. For example, in Nigeria, [23] and [41], found that female students are more likely than males to experience depression. Similarly, the present study supported the result of a study in a Taiwan university which also found that female students were more likely to seek professional psychological help than male students, an indication of depressive symptoms. However,[52] argued that female vulnerability to mental health problems is associated with a type of genetic predisposition, rather than purely environmentally sex differences. Other studies postulated that women in general are more prone to over report medical symptoms than men $[52 ; 53]$.

With regard to wellbeing and gender, the result indicated that female students reported higher wellbeing index than male students despite high stress and depression suggesting that stress and depression affects male health than female health or there may be a protective effect for female students such as higher income, social support and religious participation which have being associated with higher wellbeing in the presence of high stress and depression. Similarly, El Ansari et al [54] in a study among students in Egypt found that a higher percentage of female students (86\%) compared to $(77 \%)$ of male students rated their health status as excellent/very good. Consequently there is a need for more studies to examine how female students welling resist greatly the influence of stress and depression more than their male counterparts. 


\section{Conclusion}

This study focused mainly on the association of stress and depression with wellbeing and gender of university students in Nigeria. Literature evidence indicates that the findings from this study have not been presented in Nigeria, which makes comparison with previous studies difficult. However, the study shows that more female students reported stress and depression than male students but they were able to bounce back to a better general health and wellbeing than male students which though have lower stress and depression but are not able to transmit it to a better wellbeing. This study recommends a further study with male data both qualitative and quantitative to understand the correlation between mental health indicators and wellbeing among male students in Nigeria. It will be also important to include in such a study the masking effect of cigarettes smoking, use of hard drugs and alcohol use by male students.

\section{Compliance with ethical standards}

\section{Acknowledgments}

The assistance of the HOD of Public Health of the University of Calabar Prof. Nwadiaro is well appreciated.

\section{Disclosure of conflict of interest}

There is no conflict of interest arising from this study.

\section{Statement of informed consent}

Before data collection for the study, informed consent was obtained from all students participants as stated in section 2 (2.1)

\section{References}

[1] WHO. Depression Episode, international classification of diseasesICD-10, Chapter 5, F32. 2006.

[2] WHO. WHO Maps: Non-communicable disease trend in all countries, World Health Global Report, World Health Organization. 2011.

[3] Fawibe AE, Shittu AO. Prevalence characteristics of cigarette smokers among undergraduates of the University of Ilorin. Nigerian Journal of Clinical Practice. 2011; 14: 201-205.

[4] Agwu ME, Draper SB, De Ste, Croix M. Depressive Symptoms Life Satisfaction and Cognitive Health Status among University Students in Nigeria by Gender and Ethnicity. American Journal of Health Research. 2017; 5(2): 25-37.

[5] Dyson R, Renk K. Freshmen adaptation to university life: depressive symptoms, stress and coping. Journal of Clinical psychology. 2006; 62(10): 1231-1244.

[6] Wang D, Ou C, Chen M, Duan N. Health-promoting lifestyles of university students in Mainland China. Journal of the British Medical Council of Public Health. 2009; 9: 379.

[7] WHO. Promoting mental health. World Health Organizations report. 2005; 27.

[8] Hubert M, Knottnerus JA, Green L, Jadad AR, Van der Horst H, Kromhout D, Leonard B, Lorig K, Loureiro MI, Van der Meer JWM, Schnabel P, Smid H. How should we define health? British Medical Journal. 2011; 343 : d4163.

[9] National Bureau of Statistics. (NBS, 2010). The review of the Nigerian economy. 2010.

[10] Garrusi B, Safizadch H, Pourhosseni O. A study on the Lifestyle of the Iranian university students. Iranian Journal of psychiatry and Behavioural Sciences. 2008; 2(2).

[11] Schmidt M. Predictors of self-rated health and lifestyle behaviours in Swedish university students. Global Journal of Health Science. 2012; 4(4): 1-14.

[12] Omigbdum 00, Onibokun AC, Yusuf BO., Odukogbe AA, Omigbodun AO. Stressors and counselling needs of undergraduate Nursing students in Ibadan, Nigeria. Journal of Nursing Education. 2004. 43(9).

[13] Jegede PO. Predictors of JAVA programming self-efficacy among engineering students in Nigerian university. International Journal of computer science and information security. 2009; 4(1\&2).

[14] Salami SO. Occupational stress and well-being: Emotional intelligence, self-efficacy, coping, negative affectivity and social support as moderators. Journal of International Social Research. 2010; 3(12). 
[15] Aregbeshola RA. The political, economic and dynamics of Nigeria: A synopsis. Asian Briefing. 2011; 39: 1-7.

[16] Philips DA. Nigeria geography. Philadephia; Chelsea House. 2004.

[17] Walker, N.J. and R.E. Schulze, 2008: Climate change impacts on agro-ecosystem sustainability across three climate regions in the maize belt of South Africa. Agriculture, Ecosystems and Environment, 124(1-2), 114-124Terrass F, Benjelloun M. (2010). The effect of water shortages on health and human development. Perspectives in Public health, 132(5).

[18] Keyes C.L (2002) The Mental Health Continuum From languishing to flourishing in life. Journal of Health and Social Behaviour, 43 (2). 2007-222.

[19] Stewart- Brown et al (2002). Health Status of People Using Complementary and Alternative Medical Practitioner Services in 4 English Counties.

[20] Sabbah I, Sabbah H, Khamis R, Sabbah S, Droubl N. Health related quality of life of university students in Lebanon: lifestyles behaviours and socio-demographic predictors. Open Access Journal. 2013; 5(714): 1-12.

[21] Kuk JF, Ardern CI. The influence of ethnicity and gender on the association between measured obesity and cardiorespiratory fitness with self-rated overweight, physical activity and health. Perspectives in public Health. 2014; 134(1).

[22] Zawawi JA, Hamaideh SH. Depressive symptoms and their correlates with locus of control and satisfaction with life among Jordanian college students. Europe's Journal of Psychology. 2009; 71-103.

[23] Adewuya AO, Ola BA, Aloba 00, Mapayi BM, Oginni 00. Depression amongst Nigerian university students. Journal of Social Psychiatry and Psychiatry Epidemiology. 2006; 41: 674-678.

[24] American College Health Association. (ACHA, 2010). National College health assessment Fall, 2010 reference group executive report. Retrieved June 6, 2011 from http://www.acha-ncha.org/docs/ACHANCHA11_ReferenceGroup_Executive Summary_Fall2010.pdf.

[25] Nazroo J. The structuring of ethnic inequalities in health: Economic position, racial discrimination and racism. American Journal of Public Health. 2003; 93(2): 277-284.

[26] Varela-Mato V, Cancela JM, Ayan C, Martin V, Molina A. Lifestyle and health among Spanish university students: Differences and academic discipline. International Journal of Public Health. 2012; 9: 2728-2741.

[27] American College Health Association. (ACHA, 2010). National College health assessment Fall, 2010 reference group executive report. Retrieved June 6, 2011 from http://www.acha-ncha.org/docs/ACHANCHA11_ReferenceGroup_Executive Summary_Fall2010.pdf.

[28] Hinkle, E. (1987). Stress and disease, the concept after 50 years. Journal of Social Science Medicine, 25(6), 561566.

[29] WHO. (2007). Depression Episode, international classification of diseasesICD-10, Chapter 5, F32. Retrieved on November, 19, 2008, from http://www.who.int/classification/appa/icd10online.[AccessedEL-Gilang A, Amr M, Awadalla N, EL-Khawaga G. Stress among medical and law students in Mansoura, Egypt. Middle East Journal of Family Medicine. 2008; 6(9).

[30] EL-Gilang, A., Amr, M., Awadalla, N., \& EL-Khawaga, G. (2008). Stress among medical and law students in Mansoura, Egypt. Middle East Journal of Family Medicine, 6 (9).

[31] Bayram N, Bilgel N. The prevalence and socio-demographic correlations of depression, anxiety and stress among a group of university students. Journal of Social Psychiatry and Psychiatry Epidemiology. 2008; 43: 667-672.

[32] Kaya M, Genc M, Kaya B, Pehlivan E. Prevalence of depressive symptoms, ways of coping and related factors among medical school and health services higher education student. Turkish Journal of Psychiatry. 2007; 18(2): 137-146.

[33] Lindsey BJ, Fabiano PSC. The prevalence and correlates of depression among college students. College Student Journal. 2009; 43(4).

[34] Mikolajczyk RT, Maxwell AE, Naydenova V, Meier S, Ansari W. Depressive symptoms and perceived burdens related to being a student: Survey in three European countries. Journal of Clinical Practice and Epidemiology in Mental Health. 2008; 4: 19.

[35] Marshall LL, Allison A, Nykamp D, Lanke S. Perceived stress and quality of life among doctors of pharmacy students. American Journal of Phamacology Education. 2008; 15, 72(6): 137. 
[36] Wang D, Ou C, Chen M, Duan N. Health-promoting lifestyles of university students in Mainland China. Journal of the British Medical Council of Public Health. 2009; 9: 379.

[37] Hafen, M., Reisbig, A. M., White, M. B., \& Rush, B. R. (2006) predictors of depression and anxiety in first year veterinary students: A preliminary report. Journal of Vetinary Medical Education, 33(3), 432-440.

[38] Bostanci, M., Ozdel, O., Oguhanoglu, N. K., \& Veark, M. (2005) Depressive symptomatology among university students. Croatian Medical Journal, 46(1), 96-100.

[39] Lepore SJ, Miles HJ, Levy JS. Relation of chronic and episodic stressors to psychological distress, reactivity, and health problems. International Journal of Behavioral Medicine. 1997; 41: 39-59.

[40] Eller, T., Aluoja, A., Vasar, V., \& Veldi, M. (2006). Symptoms of anxiety and depression in Estonian medical students with sleep problems. Journal of Depression Anxiety, 23:250-256.

[41] Aniebue P, Onyema G. Prevalence of depressive symptoms among Nigerian medical undergraduates. Royal Society of Medicine press. 2008; 38(3): 157-158.

[42] Dahlin, M., Joneborg, N., \& Runeson, B. (2005). Stress and depression among medical students: A cross-sectional study. Journal of Medical Education, 39, 594-604.

[43] Dusselier l, Dunn B, Wang Y, Shelley MC, Whalen DF. Personal, health, academic and environmental predictors of stress for residence hall students. Journal of American Collage Health. 2005; 54(1).

[44] Agwu ME. The Impact of Socio-demographic Factors on Oral Health Status (halitosis) among Students in the University of Calabar, Calabar, Cross River State, Nigeria. International Journal of Health and Social Studies. 2020; $9(6)$.

[45] Nellor, D. C. L. (2008). The Rise of Africa's 'Frontier' Markets Finance and development, IMF 45(3): 30-33.

[46] CIA. (2014). The world fact book: "Nigeria". Retrieved October, 12, 2014, from http://www.cia.gov/cia/publications/factbooks/geos/ni.htm/.

[47] Mackenbach, J., \& Baker, M. (2002). Reducing inequalities in Health: A European perspective. London; Routledge.

[48] Marmot, M. (2005). Social determinants of health and inequalities. Lancent, 365:1099-104

[49] Dahlgren, G., \& Whitehead (1991). In Lewis, G. H., Sheringham,J., Kalim, K., \& Crayford J. B. T. (Eds.), Mastering public health: A postgraduate guide to examinations and revalidation. London, Edward Arnold, pp. 277-278.

[50] Stock, C., Misevicience, I., Grima, G., Petkeviciene, J., Ontoso, A. \& Kramer, A. (2003). Differences in health complaints among university students from three Europeam countries. Journal of Preventive Medicine, 37, 353343.

[51] Sanya AO, Ogwumike O0, Ige AP, Ayanniyi OA. Relationship of waist-hip ratio and body mass index to blood pressure of individuals in Ibadan North local government. African Journal of Physiotherapy and Rehabilitation Sciences. 2009;1(1):7-11.

[52] Salami SO. Occupational stress and well-being: Emotional intelligence, self-efficacy, coping, negative affectivity and social support as moderators. Journal of International Social Research. 2010; 3(12).

[53] Abdel-khalek A, AL Ansari W. Gender differences in anxiety among undergraduates from ten Arab countries. Journal of Social Behaviour and Personality. 2004; 32 (7): 649-656.

[54] Stock, C., Mikolajczyk, R.T., Bilir, N., Petkeviciene, J., Naydenova V., Dudziak, U., Marin-Fernandez, B., \& EL Ansari, W. (2007) Gender differences in students' health complaints: A survey in seven countries. Journal of Public Health, $16(5), 353-360$.

[55] El Ansari W, Oskrochi R, Stock C. Symptoms and health complaints and their association with perceived stress: Students from seven universities in England, Wales and Northern Ireland. Journal of Public Health. 2013; 21(5): 413-425. 